\title{
Structural and corrosion behaviour of stoichiometric and substoichiometric TiN thin films
}

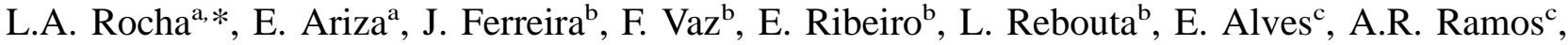 \\ Ph. Goudeau ${ }^{\mathrm{d}}$, J.P. Rivière ${ }^{\mathrm{d}}$ \\ ${ }^{a}$ Universidade Minho, Dept. Eng Mecânica, Campus Azurém, 4800-058 Guimarães, Portugal \\ ${ }^{\mathrm{b}}$ Universidade Minho, Dept. Física, Campus Azurém, 4800-058 Guimarães, Portugal \\ ${ }^{\mathrm{I}}$ ITN, Departamento de Física, E.N.10, 2685 Sacavém, Portugal \\ ${ }^{\mathrm{d}}$ Université de Poitiers, Laboratoire de Métallurgie Physique, 86960 Futuroscope, France
}

\begin{abstract}
This paper reports the structural and electrochemical behaviour of $\mathrm{TiN}_{x}$ thin films prepared by d.c. reactive magnetron sputtering. $\mathrm{X}$-Ray diffraction showed the development of the hexagonal $\alpha$-Ti phase, with strong [002] orientation, for low nitrogen contents. For nitrogen contents of 20 and 30 at.\%, the $\varepsilon-\mathrm{Ti}_{2} \mathrm{~N}$ phase appears with [200] orientation. With further increasing the nitrogen content, the $\delta$-TiN phase becomes dominant. Composition and the resulting changes in microstructure (crystalline phases and the lattice distortion induced by the growth conditions) are the two main parameters that seem to rule coating properties. Results of potentiodynamic polarisation tests showed that all films have a high corrosion resistance reflected by corrosion current densities below $0.7 \mu \mathrm{A} / \mathrm{cm}^{2}$. Also, electrochemical impedance spectroscopy tests corroborated the results obtained in the polarisation tests, showing that films containing low percentages of nitrogen (less than 8\%) reveal the best corrosion resistance. Further increases in nitrogen content lead to a decrease in the corrosion resistance. An exception to this behaviour was found for the film with 30 at. $\% \mathrm{~N}$. This sample presents an excellent corrosion resistance, which in fact, increases with the immersion time. Higher nitrogen contents (52 and 55 at.\%) promote a relative increase in the corrosion resistance when compared with 50 at.\% films. This behaviour might be explained by the particular microstructural characteristics of the films.
\end{abstract}

(c) 2003 Elsevier B.V. All rights reserved.

Keywords: Titanium nitride; Structural properties; Sputtering; EIS; Corrosion resistance

\section{Introduction}

The continuous progress in thin film technology is largely connected to the adjustment of structural and chemical properties of the films to actual applications. The resulting demands for increased sophistication of thin film structures can only be achieved by an appropriate choice and control of the overall parameters governing the deposition process. Besides the deposition parameters related with the film growth, stoichiometry has to be considered as one of the essential parameters for determining the microstructural properties and chemical binding conditions of the growing film. In this respect, thin films elaborated through physical vapour deposition (PVD) processes are well known to exhibit

\footnotetext{
*Corresponding author. Tel.: +351-253510231; fax: +351253516007.

E-mail address: 1rocha@dem.uminho.pt (L.A. Rocha).
}

a microstructure that is strongly-dependent on these stoichiometric features $[1,2]$.

Stoichiometric titanium nitride (TiN) is one of the most important technological coating materials, not only because of its excellent tribological properties but also due to a good chemical stability. It is used in a wide range of applications, which vary from a protective material for machine parts and cutting tools [3] to diffusion barriers in semiconductor technology [4]. In the past, properties of substoichiometric titanium nitride $\left(\mathrm{TiN}_{x}\right.$ ) have been studied by comparably few researchers considering only basic properties such as hardness, phase composition or lattice distortion [5-9]. All these investigations focused mainly on the $\delta$-TiN-phase, whereas little attention was paid to the properties of the $\mathrm{N}$ containing $\alpha$-Ti.

In this paper, the electrochemical properties of substoichiometric $\operatorname{TiN}_{x}$ coatings are studied aiming an accurate 
understanding of its evolution as a function of the $\mathrm{N}$ content.

\section{Experimental details}

The $\operatorname{TiN}_{x}$ samples were deposited by reactive d.c. magnetron sputtering, from a high purity Ti target onto polished high-speed steel (AISI M2) and silicon substrates. The depositions were carried out in a 'homemade' apparatus in an $\mathrm{Ar} / \mathrm{N}_{2}$ atmosphere [10]. The system consists of two vertically opposed rectangular magnetrons in a closed field configuration. A pure titanium adhesion layer of $\sim 0.40 \mu \mathrm{m}$ was deposited on the substrates prior to coating deposition. The target to substrate distance was kept at $70 \mathrm{~mm}$ in all runs and the substrate holder was rotating over the targets at a constant frequency of $7 \mathrm{rev}$. $/ \mathrm{min}$. The base pressure in the deposition chamber was typically in the order of $10^{-4} \mathrm{~Pa}$ and rose to values approximately $4 \times 10^{-1} \mathrm{~Pa}$ during depositions. Substrates were d.c. biased with a potential of $-70 \mathrm{~V}$ and a temperature of approximately $250{ }^{\circ} \mathrm{C}$ during depositions. The experiments were carried out with the titanium target coupled to a d.c. power supply: $I=1 \times 10^{-2} \mathrm{~A} / \mathrm{cm}^{2} ; \mathrm{V} \approx 400 \mathrm{~V}$.

Composition of the deposited layers was obtained by Rutherford backscattering (RBS). Sample thickness was determined by an average of five ball-cratering (BC) experiments and confirmed by scanning electron microscopy (SEM). Morphology was examined by SEM, while $\mathrm{X}$-ray diffraction (XRD) was used for structural characterisation.

The electrochemical tests were carried out at room temperature in an artificial sweat solution, $(\mathrm{pH} 4.57)$ containing $7.5 \mathrm{~g} \mathrm{l}^{-1} \mathrm{NaCl} ; 1.2 \mathrm{~g} \mathrm{l}^{-1} \mathrm{KCl} ; 1 \mathrm{~g} \mathrm{l}^{-1}$ $\mathrm{CH}_{4} \mathrm{~N}_{2} \mathrm{O}$ (urea) and $1 \mathrm{ml}^{-1} \mathrm{C}_{3} \mathrm{H}_{6} \mathrm{O}_{3}$ (lactic acid). All measurements were conduced in a standard three-electrode cell. A saturated calomel electrode (SCE) was used for the potential measurements. A PGP201 Potentiostat/Galvanostat (Radiometer Denmark), controlled by the VoltaMaster software, was used to carry out the polarisation measurements and a Voltalab PGZ100 Potentiostat (Radiometer Analytical), controlled by the VoltaMaster-4 software, was used for the EIS measurements. Prior to polarisation tests the open circuit potential (OCP) was monitored during $3600 \mathrm{~s}$, after which the samples were anodically polarised from -800 to $2000 \mathrm{mV}$ at a scan rate of $2 \mathrm{mV} . \mathrm{s}^{-1}$. The EIS measurements were performed in the frequency range from 100 $\mathrm{kHz}$ to $10 \mathrm{MHz}$, with an $\mathrm{AC}$ sine wave amplitude of 10 $\mathrm{mV}$ applied to the electrode at its corrosion potential. EIS measurements were performed at increased immersion times (60 min, 1, 2 and 3 days). For EIS data simulation the ZView2 software was used.

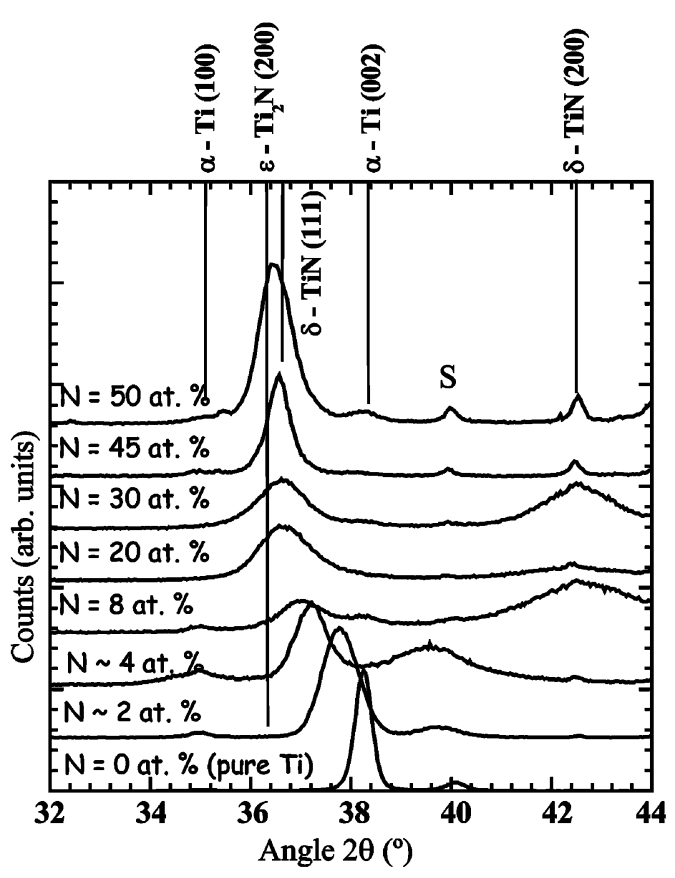

Fig. 1. Evolution of the XRD patterns of $\mathrm{TiN}_{x}$ films as a function of nitrogen contents. $\mathrm{S}$ corresponds to the diffraction lines of the substrate.

\section{Results and discussion}

\subsection{Structural characterisation}

The investigation of $\operatorname{TiN}_{x}$ films deposited by different PVD techniques shows that increasing nitrogen flows and then the gas pressure during the deposition process leads to gradually higher nitrogen contents in the films $[6,8]$. A closer look to the XRD diffraction patterns reveals the development of the hexagonal $\alpha$-Ti phase with strong [002] orientation for low nitrogen contents (Fig. 1). The diffraction peaks are progressively shifted towards lower diffraction angles as the $\mathrm{N}$ content increases. For nitrogen contents of 20 and 30 at.\%, the $\varepsilon-\mathrm{Ti}_{2} \mathrm{~N}$ phase appears with a [200] orientation. Furthermore, and although it does not seem clearly visible, the $\delta$-TiN phase might be already developing. The broad diffraction lines do not allow concluding unambiguously concerning the exact nature of the crystalline compounds present whereas the phase diagram predicts only the $\varepsilon$ $\mathrm{Ti}_{2} \mathrm{~N}$ phase as well as the $\alpha$-Ti [11], but with diffraction peaks shifted to lower diffraction angles due to nitrogen insertion. With further increasing the nitrogen content, the $\delta$-TiN phase becomes dominant.

The titanium-nitrogen phase diagram is complex, but basically Ti crystal is said to be an 'interstitial' crystal where $\mathrm{N}$ atoms fit into the gaps of the Ti structure [11]. This structure evolves from hexagonal $\alpha$-Ti (space group $\mathrm{P} 63 / \mathrm{mmc}$ ), to face-centred-cubic $\delta$-TiN (space group 


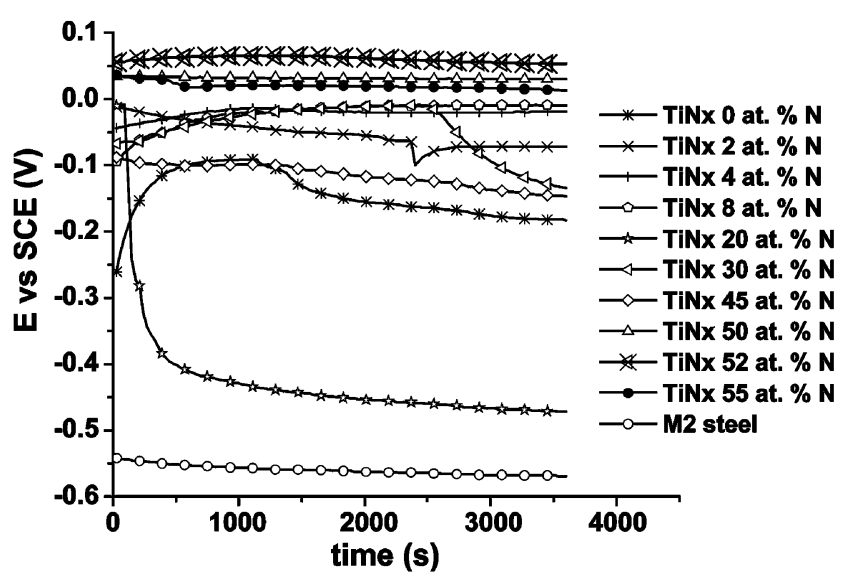

Fig. 2. Evolution of corrosion potential $\left(E_{\text {corr }}\right)$ with time for the $\mathrm{TiN}_{x}$ films.

Fm-3 m), the $\mathrm{N}$ atoms being into octahedral sites of the Ti lattice as the amount of nitrogen is increased. The $\alpha-$ Ti lattice is able to accept small amounts of nitrogen at octahedral sites [11], but since PVD is a thermodynamically non-equilibrium process, the $\alpha$-Ti lattice may be forced to accept more nitrogen atoms due to hindered mobility of the deposited particles [6,11]. Therefore an oversaturated metastable solution of nitrogen in titanium is formed for the lower $\mathrm{N}$ contents. The shift in the diffraction lines revealed by Fig. 1 is thus a consequence of this progressive increase of $\mathrm{N}$ interstitials in octahedral $\alpha$-Ti sites, which causes lattice distortion and thus diffraction peak broadening.

\subsection{Corrosion behavior}

After being immersed in the artificial sweat solution, the corrosion potential $\left(E_{\text {corr }}\right)$ of the samples was monitored for $60 \mathrm{~min}$. The obtained curves are plotted in Fig. 2. For comparison the behaviour of the M2 steel, used as a substrate, is also plotted. As it can be observed, most samples achieve a steady-state after a relatively short immersion time. An exception occurred for the sample containing 20 at. $\% \mathrm{~N}$, in which an abrupt decrease in the potential was recorded after $7 \mathrm{~min}$ of immersion. This may be considered as an indication of less stable film formed in this sample, probably with a larger amount of porosity. Another remark should be made to the film with 30 at. $\% \mathrm{~N}$, where a sudden decrease in the corrosion potential was observed, starting after ca. $2500 \mathrm{~s}$ of immersion. The behaviour of this sample will be discussed below. In Fig. 3 the steadystate $E_{\text {corr }}$ values, obtained after 60 min of immersion, are plotted as a function of the $\mathrm{N}$ content of the film. In the same graph the evolution of the coating thickness with the amount of $\mathrm{N}$ is plotted as well. Considering the $E_{\text {corr }}$ values, three distinct behaviours may be observed:



Fig. 3. Corrosion potential (after $60 \mathrm{~min}$ immersion) and coating thickness as function of nitrogen content of the films.

- as the $\mathrm{N}$ content increases up to 8 at. $\%$ the corrosion potential becomes nobler in nature;

- in comparison, the films containing 30 and 45 at.\% N present a much more active $E_{\text {corr }}$;

- the sample with stoichiometric composition and the films containing more than 50 at.\% $\mathrm{N}$ are those presenting lower thermodynamic tendency to corrode.

The graph of Fig. 3 also suggests that coating thickness by itself is unable to explain the corrosion behaviour of the films. For instances, the graph shows that films presenting the noblest behaviour $(50,52$ and 55 at. $\% \mathrm{~N})$ are the thinner ones. Therefore, microstructure is likely to play an important role on the definition of the corrosion behaviour of the films.

Fig. 4 presents the range of variation of the polarisation curves representative of the behaviour of each film. For comparison, the polarisation behaviour of the substrate is also plotted in this figure. As it can be observed,

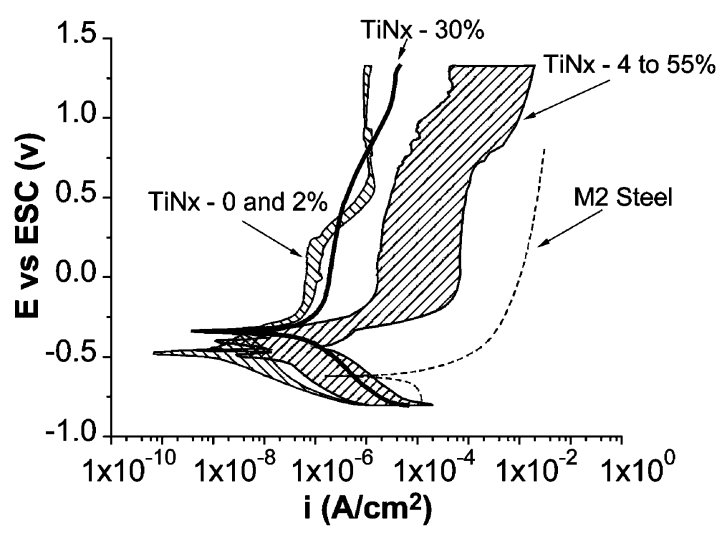

Fig. 4. Anodic polarisation curves obtained for films immersed in artificial sweat solution. 


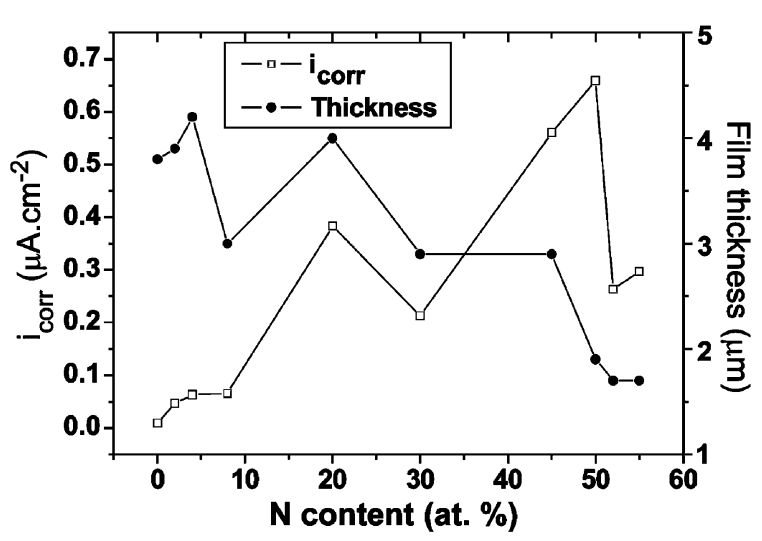

Fig. 5. Influence of the $\mathrm{N}$ content on the corrosion current density $\left(i_{\text {corr }}\right)$ and film thickness.

most films appear to present two separate pseudopassive regions. Nevertheless a distinction can be made between samples. For very low nitrogen contents ( 0 and 2 at.\%) low passive current densities are observed, which can be one to three times lower in magnitude when compared to the other films. Considering the other samples, it was possible to observe that in general, an increase in nitrogen content seems to be related with an increase in the passive current densities. However, as shown in the figure, the film with 30 at. $\% \mathrm{~N}$ presents passive current densities similar to the samples with very low $\mathrm{N}$ content, namely the sample with $0 \%$ of $\mathrm{N}$. Also, in this sample, the distinction between the two passive plateaus is not very clear. Considering again the results shown in Fig. 3, it can be seen that, after starting to decrease in magnitude, the $E_{\text {corr }}$ also tend for values approaching that of the $0 \% \mathrm{~N}$ film. As the adhesion layer in all samples is of titanium, this behaviour suggests that in this sample penetration of the solution down to the $\mathrm{Ti}$ adhesion layer occurs. This aspect was confirmed by observation of the sample by SEM.

From the polarisation curves presented in Fig. 4, the electrochemical parameters were determined and in Fig. 5 the evolution of the corrosion current density $\left(i_{\text {corr }}\right)$ with the amount of nitrogen is presented. In the graph the evolution of the film thickness with the $\mathrm{N}$ content is also plotted. A first remark should be made to the fact that the corrosion current densities are always relatively low in magnitude, being in all cases inferior to $0.7 \mu \mathrm{A} \mathrm{cm}{ }^{-2}$. If one compares these values with that obtained in the steel substrate $\left(48.9 \mu \mathrm{A} \mathrm{cm}^{-2}\right)$, we can conclude that, in general, $\operatorname{TiN}_{x}$ films have a strong protective characteristic when applied to steel. Again, as referred above, the graph still shows that the variation in film thickness does not explain by itself the variations in corrosion current.

An increase in the $\mathrm{N}$ content appears to give origin to an increase in the corrosion current densities. However, two different trends may be observed in the graph, with the samples with 30,52 and 55 at.\% $\mathrm{N}$ presenting $i_{\text {corr }}$ values much lower than the samples with 20,45 and 50 at.\%. These results are in good agreement with the results concerning corrosion tendency $\left(E_{\text {corr }}\right)$ presented in Fig. 3, with the exception of the sample with 50 at. $\%$ N. In fact, Fig. 3 shows that the $E_{\text {corr }}$ values of the stoichiometric sample are of the same order of magnitude of the films with excess of $\mathrm{N}$ (52 and 55 at.\%). Nevertheless, in Fig. 5 one can see that the 50 at.\% $\mathrm{N}$ film has a very high corrosion rate when compared with the other samples.

Fig. 6 shows SEM micrographs taken after the polarisation tests and representative of the morphology of the surface of the samples containing 50,52 and 55 at.\% $\mathrm{N}$, are presented. It can be observed that the polarisation test resulted in pitting of the surface in all samples. However, the amount of pitting is strongly influenced by the amount of nitrogen in the film, or, in other words, appears to be proportional to the $i_{\text {corr }}$, being higher for the 50 at.\% $\mathrm{N}$ and decreasing for the 52 and 55 at.\% $\mathrm{N}$ samples. As shown in the detail presented in Fig. 6d, pitting is likely to expose the Ti adhesion layer and the substrate to the solution. As a consequence, galvanic effects may arise, which are expected to have a catastrophic effect on the substrate [12]. The surface morphology and cross-section views of those films are presented in Fig. 7. As it can be seen, in all cases films are characterised by columnar growth. However, it can be observed that films containing nitrogen in excess seems to present denser structures than the stoichiometric film. In other words, if the 50 at. $\% \mathrm{~N}$ film has a columnar structure less dense than the other two samples, penetration of the corroding solution through the film is likely to become facilitated, and thus a higher corrosion rate arises.

In Fig. 8, the polarisation resistance estimated from the results of the EIS experiments are plotted. Measurements were performed after 1, 2 and 3 days of immersion. It should be referred that polarisation resistance is an electrochemical parameter inversely proportional to the corrosion rate. Thus, for comparison, the $i_{\text {corr }}$ values obtained from the potentiodynamic polarisation experiments are also plotted in the graph (please note that the $i_{\text {corr }}$ axis is sorted in the descending order). Equivalent circuit models were simulated in order to allow the deduction of $R_{\mathrm{ps}}$ and $R_{\mathrm{pf}}$ values. After, the estimation of the polarisation resistance was calculated by the sum of the substrate polarisation resistance $\left(R_{\mathrm{ps}}\right)$ and the film polarisation resistance $\left(R_{\mathrm{pf}}\right)$, according to the method described by Liu et al. [13]. A very good agreement between the fitted and experimental data was always obtained.

As it can be seen in the graph, a good agreement was found between the polarisation resistance values estimated from the EIS and the $i_{\text {corr }}$ values calculated from the polarisation curves. Regarding the polarisation resis- 

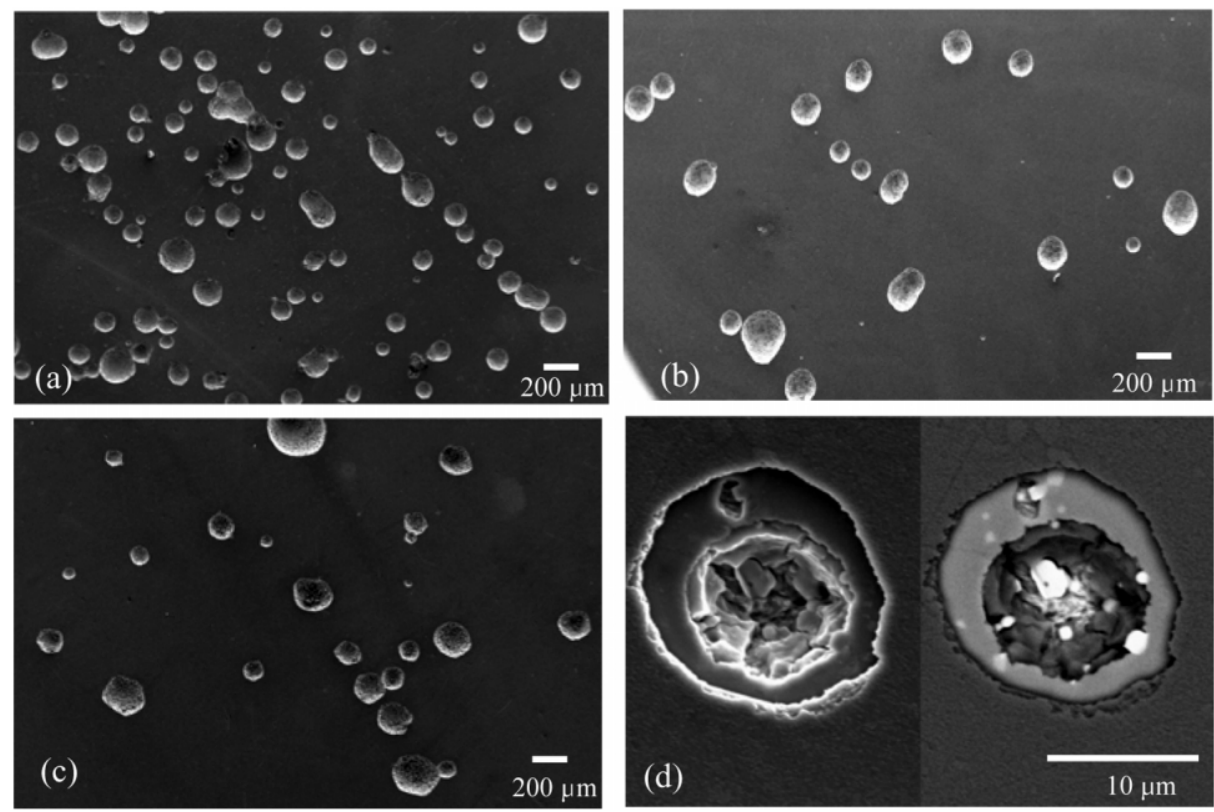

Fig. 6. SEM micrographs obtained for $\mathrm{TiN}_{x}$ films after polarisation tests in artificial sweat solution. (a) 50 at.\% $\mathrm{N}$, (b) 52 at.\% $\mathrm{N}$, (c) 55 at.\% $\mathrm{N}$ and (d) pitting of a polarised sample, with exposure of both the Ti adhesion layer and the substrate.

tance of the samples with higher $\mathrm{N}$ amounts $(50,52$ and 55 at.\%), the resistance polarisation appears to be almost independent of the immersion time, this being an indication of a high stability of the coatings when in contact with the solution. Nevertheless, probably due to the character of the columnar structure that characterises the sample with the stoichiometric composition, its polarisation resistance is always lower than that of the films containing an excess of nitrogen.
Also, samples containing low amounts of nitrogen both high $R_{\mathrm{ps}}$ and $R_{\mathrm{pf}}$ values were obtained at low immersion times (1 day), resulting in an overall high polarisation resistance. However, for these samples, data plotted in Fig. 8 show that polarisation resistance is strongly reduced when the immersion time increases up to 3 days, this being an indication of the detrimental effect of the solution on the characteristics of the film. An exception is the behaviour of the 30 at. $\% \mathrm{~N}$ film in
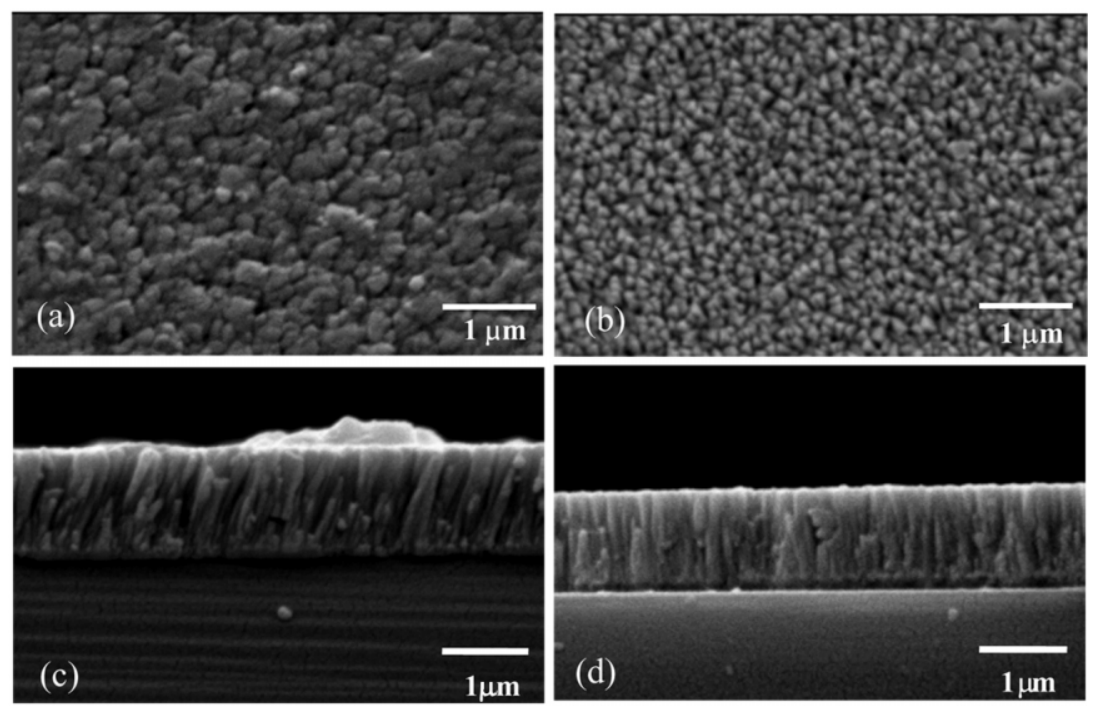

Fig. 7. Surface morphologies and aspect of cross-sections of $\mathrm{TiN}_{x}$ films. (a) 50 at. $\% \mathrm{~N}$, (b) 52 at. $\% \mathrm{~N}$, (c) 50 at. $\% \mathrm{~N}$ and (d) 52 at. $\% \mathrm{~N}$, respectively. 


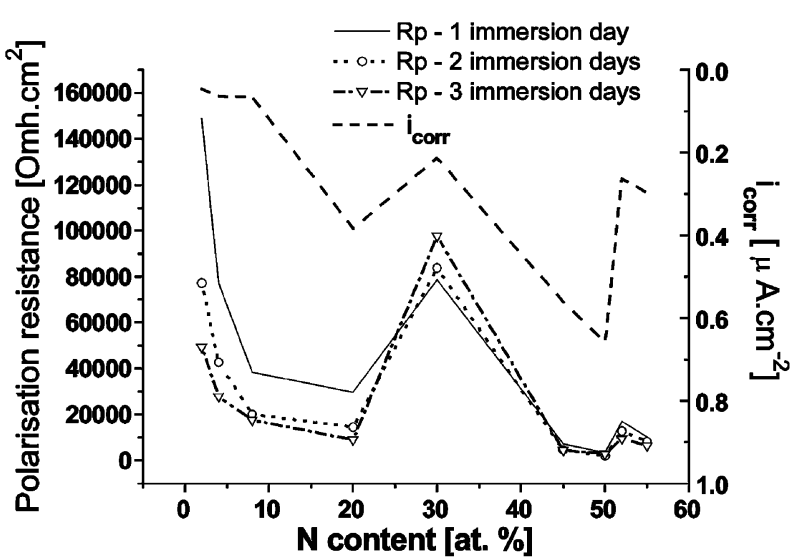

Fig. 8. Influence of the nitrogen content and immersion time on polarisation resistance of the samples. For comparison, the evolution of $i_{\text {corr }}$ with the nitrogen content is also plotted.

which, both $R_{\mathrm{ps}}$ and $R_{\mathrm{pf}}$ significantly raises with the immersion time. This aspect was already discussed in a previous work [14].

The superior corrosion resistance of the films with less than 8 at.\% $\mathrm{N}$ may be attributed to the presence of significant amounts of $\alpha$-Ti phase. Also, these samples exhibited higher film thickness (between 3.8 and 4.2 $\mu \mathrm{m})$ than the other films. The 30 at. $\% \mathrm{~N}$ sample, although presenting a relatively low thickness (ca. 2.9 $\mu \mathrm{m}$ ), is characterised by a very dense structure, which is likely to explain its high corrosion resistance.

\section{Conclusion}

Best corrosion behaviour was obtained in the TiN films containing low percentages of $\mathrm{N}$, i.e. in which the $\alpha$-Ti phase is present, characterised by a dense structure. Films near to the stoichiometric condition revealed the lowest corrosion resistance. It was observed that in these samples corrosion is influenced by the characteristics of the columnar structure of the film, which is likely to make more difficult the diffusion of the solution species down to the substrate, when the structure becomes denser as a consequence of the increase in the nitrogen content. Also, the lower thickness of these films, when compared to the low nitrogen containing films, may explain the relatively less protective character of these coatings.

A relatively high corrosion resistance was found in the 30 at. $\% \mathrm{~N}$ sample, which was attributed to the finegrained and compact structure characteristic of this sample. In addition, the 30 at. $\% \mathrm{~N}$ film presents a very high hardness, which makes it a promising solution for situations in which high corrosion and wear resistances are required.

\section{Acknowledgments}

The authors acknowledge the financial support provided by Fundação para a Ciência e a Tecnologia (FCTPortugal) to E. Ariza through the contract SFRH/BPD/ $5518 / 2001$.

\section{References}

[1] J.A. Thornton, J. Vac. Sci. Technol. 11 (1974) 666.

[2] H. Oechsner, J. Vac. Sci. Technol. A 16 (3) (1998) 1956.

[3] D.A. Glocker, S.I. Shah, Handbook of Thin Film Process Technology, 2,, IOP Publishing, Bristol and Philadelphia, 1995.

[4] H. Randhawa, Surf. Coat. Technol. 36 (1988) 829.

[5] Y. Igasaki, H. Mitsuhashi, K. Azuma, T. Muto, Jpn. J. Appl. Phys. 17 (1) (1978) 85.

[6] J.-E. Sundgren, B.-O. Johansson, S.-E. Karlsson, Thin Solid Films 105 (1983) 353.

[7] J. Stanislav, J. Sikac, M. Cermak, Thin Solid Films 191 (1990) 255.

[8] G. Berg, C. Friedrich, E. Broszeit, K.H. Kloos, Surf. Coat. Technol. 74-75 (1995) 135.

[9] M. Kawamura, Y. Abe, H. Yanagisawa, K. Sasaki, Thin Solid Films 287 (1996) 115.

[10] E. Ribeiro, A. Malczyk, S. Carvalho, L. Rebouta, J.V. Fernandes, E. Alves, et al., Surf. Coat. Technol. 151-152 (2002) 515.

[11] H.A. Wriedt, J.L. Murray, Bull. Alloy Phase Diagrams 8 (4) (1987) 378.

[12] C.V. Franco, L.C. Fontana, D. Bechi, A.E. Martinelli, J.L.R. Muzart, Corros. Sci. 40 (1998) 103.

[13] C. Liu, A. Leyand, Q. Bi, A. Matthews, Surf. Coat. Technol. 141 (2001) 164.

[14] E. Ariza, L.A. Rocha, F. Vaz, L. Rebouta, J. Ferreira, E. Alves, et al. Mater. Sci. Forum (submitted, 2003). 